\title{
A ordem social na teoria de Max Weber
}

\author{
Bruna dos Santos Bolda \\ Universidade Federal de Santa Catarina, Brasil \\ (iD) https://orcid.org/0000-0003-4588-1553 \\ bruna.bolda@hotmail.com
}

\section{Introdução}

A busca por compreender o que Max Weber quis dizer demonstra que seu pensamento ainda engendra intensas discussões no âmbito da Teoria Social. Seja no Japão (ORIHARA, 2003), na Itália (ROSSI, 2007), na França (GROSSEIN, 2005a, 2005b; COLLIOTTHÉLENNE, 2003; KAUFMANN, 2004), no México (VILLEGAS, 2014), nos países da América Latina (SELL, 2014, 2018a) ou nos Estados Unidos (KALBERG, 2012), a interpretação especializada em Max Weber "ressoa” os “ecos” da Weber-Renaissance. Especialmente os estudos motivados pelo empreendimento de republicação crítica dos escritos weberianos, a Max Weber-Gesamtausgabe, ganharam visibilidade no cenário internacional.

Se por largos anos os especialistas se ocuparam com a exegese weberiana (especialmente a primeira geração da Universidade de Hei- 
delberg, em meados da década de 1970), hoje os esforços centram-se especialmente na atualização de seus escritos. O "paradigma weberiano” defendido por Gert Albert et al (2003) e o "programa de pesquisa” de orientação weberiana proposto por Schluchter (2005) são exemplos da nova iniciativa. Essas discussões contemporâneas sobre a obra de Max Weber, particularmente as que questionam as possibilidades de microrredução existentes nos escritos do autor, revelam perspectivas por algum tempo obscurecidas. Eles contestam o clássico estatuto do "Weber individualista metodológico" a ponto de advogar, por exemplo, por uma $3^{\mathrm{a}}$ via que admite tanto a determinação do nível micro quanto do nível macro (ALBERT, 2016). Algo que, nas palavras de Carlos Sell (2014a), ajuda a “desfossilizar” a obra de Weber.

Em proximidade com o que Raquel Weiss e Rafael Benthien (2017) fazem com a obra de Émile Durkheim no Brasil, trata-se da tentativa de suplantar o Weber do "senso comum sociológico". Afinal, conforme argumentarei a seguir, podemos encontrar na teoria metodológica de Sobre algumas categorias da Sociologia Compreensiva [Über einige Kategorien der verstehenden Soziologie ${ }^{1}$ e de Conceitos Sociológicos Fundamentais [Soziologische Grundbegriffe] ${ }^{2}$ uma complexidade maior do que a do clássico estatuto do "Weber individualista metodológico”. Segundo pode-se visualizar na Figura 1, já no texto de 1913 há uma estrutura conceitual que admite formações em nível macro.

\footnotetext{
${ }^{1}$ Doravante, Kategorien (1913).

${ }^{2}$ Doravante, Grundbegriffe (1921).
} 


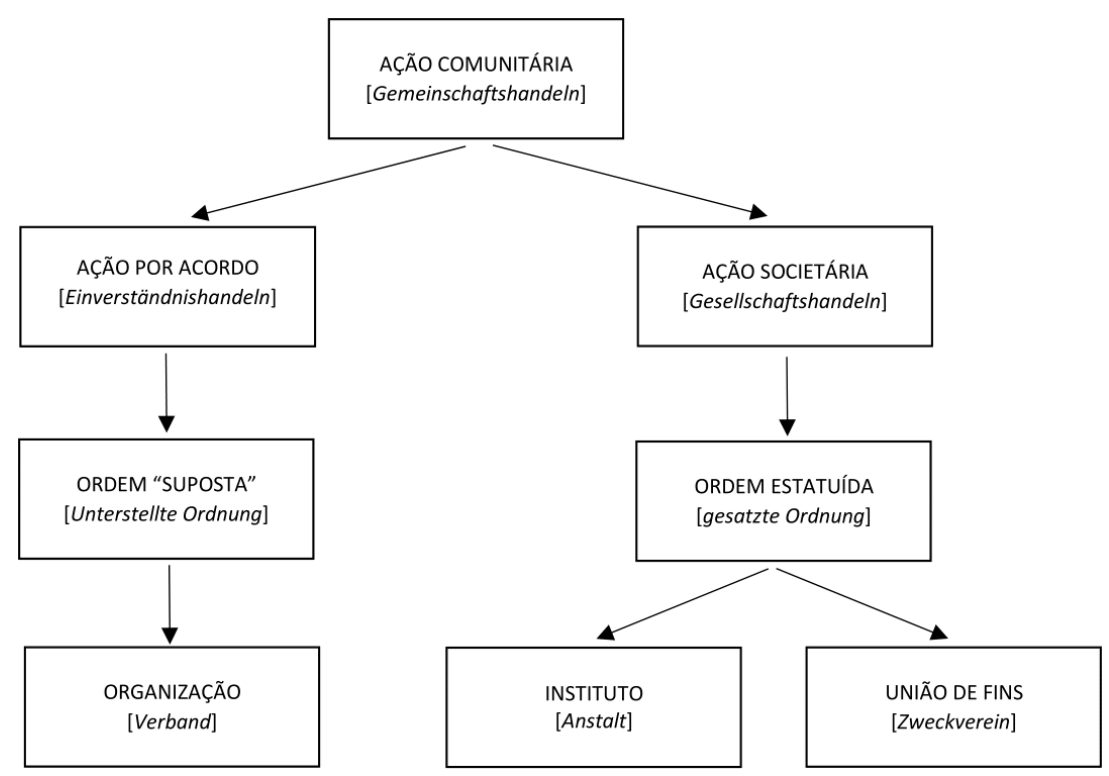

Figura 1 - Estrutura conceitual de Kategorien.

Fonte: própria autora, com base em Schluchter (2016).

Conforme argumenta Schluchter (2014), os conceitos do texto de 1921 são construídos uns sobre os outros: ação — ação social — relação social (em comunidade e em sociedade) — ordem social legítima — organização. Ainda que a "espinha dorsal" de seu esquema tenha sido mantida (como a lógica que parte do nível micro e chega ao nível macro), as terminologias foram consideravelmente modificadas. A Figura 2 ilustra tais modificações. 


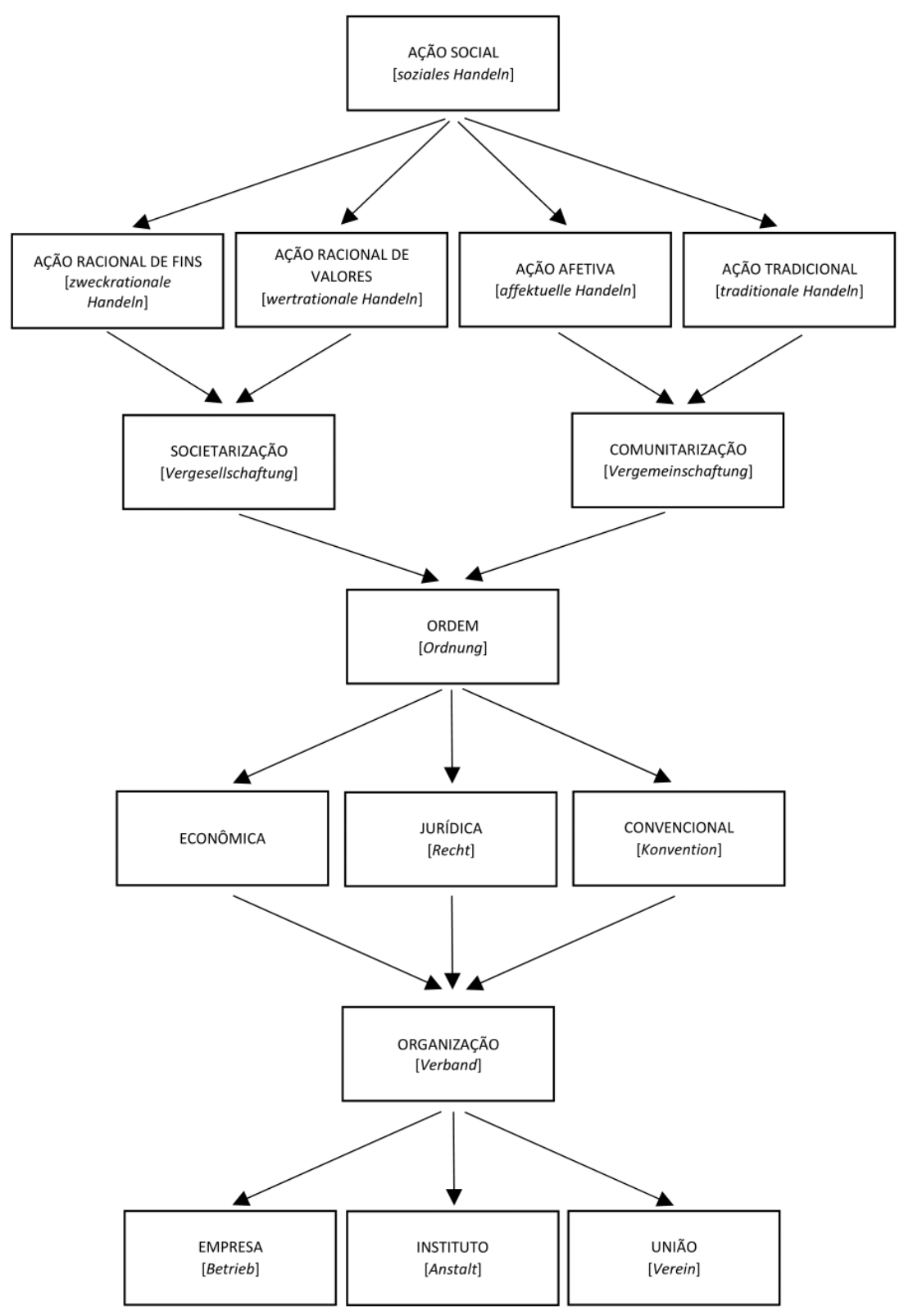

Figura 2 - Estrutura conceitual de Grundbegriffe.

Fonte: própria autora, com base em Schluchter (2016). 
A macrossociologia weberiana pode ser considerada uma teoria da institucionalização das ações sociais regulares e repetidas. Isso porque que, de acordo com Schluchter (2014), a existência de estruturas sociais aumenta a chance de que as ações no interior das ordens se desenvolvam de uma determinada forma. Assim, tanto maior a persistência das relações e ordens sociais, ${ }^{3}$ tanto maior é a chance de que as ações se desenvolvam de uma maneira específica. Em Kategorien essa chance está assegurada pelo interesse e pela legalidade (ordem estabelecida) e, segundo a interpretação de Schluchter, também é possível falar em padrões de ação assegurados pelo acordo (ordem pressuposta). Já em Grundbegriffe essa regularidade é firmada por ordens sociais (em si mesmas) ou por ordens legítimas. Ao primeiro tipo pertence a ordem econômica, enquanto ao segundo tipo pertencem as ordens legitimadas pelo dever de obediência (ordem jurídica) e pelo boicote social (ordem convencional).

São precisamente as mudanças realizadas por Weber no esquema conceitual da Sociologia Compreensiva (como a mudança de uma tipologia dual para triádica) entre 1913 e 1921, especificamente as alterações realizadas no nível macro, que pretendemos discutir neste

\footnotetext{
${ }^{3}$ Isso demonstra a despretensão consciente da teoria de Weber. Afinal, Weber (1921) não se projetou como um teórico da solução dos problemas da teoria social. Ele somente intentou analisar significados e intenções das ações regulares por meio da criação de tipos ideais. Para tanto, ele colocou sua teoria à prova e em debate com as demais abordagens de seu tempo. Stammler (1896), por exemplo, é um dos autores com os quais Weber dialoga e critica ao fundar sua noção de ordem. Weber (MWG 1/23, p. 23) afirma que Stammler cometeu um quádruplo erro: 1) conceituou erroneamente a ordem como a "forma da ação", quando, na verdade, a ordem é seu conteúdo de sentido; 2) ademais, ele inverteu a lógica argumentativa da constituição da ação pois não reconheceu que a ação se orienta por ordens, mas que, antes, as ordens são modelos de ação; 3) assim, ele ficou impossibilitado de reconhecer a relação causal entre ação e ordem; e 4) ainda, não distinguiu a aplicação normativa (legal) de um processo no interior da ordem e sua vigência empírica efetiva. Assim, ele não pôde perceber que uma ordem válida é aquela que aumenta a chance de que as ações sejam regulares.
} 
estudo. Intentamos revelar os caminhos conceituais percorridos por Weber para assentar sua teoria macro sob a égide das ações sociais e das relações sociais. Para tanto, expomos a teoria de ambos os textos com base em uma abordagem diacrônica. Inicialmente explicitamos as especificidades do primeiro texto (1913), e, depois, discutimos cautelosamente o segundo (1921). Quando oportuno, apontamos pontos de aproximações entre um e outro.

\section{A Ordem Social em Kategorien}

Na parte "antiga” de Kategorien, ${ }^{4}$ na qual Weber aborda os tipos de ação em comunidade, ${ }^{5}$ há uma explanação preliminar sobre as ordens sociais. Especificamente na seção V [Vergesellschaftung und Gesellschaftshandeln], ele introduz a Ordem estabelecida [gesatzte Ordnung] como o elemento sobre o qual a ação em sociedade (ação orientada por um estatuto formalizado) assenta as suas expectativas. No Quadro 1 há o trecho de Kategorien no qual Weber conceitua a

\footnotetext{
${ }^{4}$ A primeira parte do ensaio foi escrita no verão de 1913, e, por isso, possui terminologias semelhantes às do capítulo sobre religião de $W u G$ - que também foi escrito no verão do mesmo ano. Nessa parte Weber se dedica a elucidar as especificidades da Sociologia Compreensiva. Tal Sociologia não se fundamenta nem em bases psicológicas nem em bases normativas, e, por isso, se distancia das ciências dogmáticas. Antes, ela atenta para o sentido subjetivamente visado da ação. Já o período de escrita da segunda parte do ensaio é alvo de controvérsias. Numa carta enviada a Rickert, em 5 de setembro de 1913, Weber fala que a segunda parte do texto estava finalizada há 3/4 anos. Isso é passível de duas interpretações: pode-se inferir tanto que " $3 / 4$ " são 3 ou 4 anos quanto que " $3 / 4$ ” são três quartos de um ano (ou seja, 9 meses). Ainda que não tenhamos exatidão da data de escrita, sabemos que a segunda parte do texto é anterior à primeira (SCHLUCHTER, 2014). Ela pode ter sido escrita entre 1909 e 1910 ou em 1912.

${ }^{5} \mathrm{~A}$ ação em comunidade [Gemeinschaftshandeln] (ação que refere seu sentido subjetivo ao comportamento de outras pessoas) é o objeto da análise sociológica de Kategorien. Quando orienta-se por um estatuto formalizado, ela é de tipo societário [Gesellschaftshandeln]. Quando, por outro lado, ela refere-se a uma ordem tacitamente compreendida, há uma ação por acordo [Einverständinishandeln].
} 
gesatzte Ordnung.

Quadro 1 - Conceito de ordem social em Kategorien.

\begin{tabular}{|c|c|}
\hline \multirow{4}{*}{1913} & TRECHO ORIGINAL \\
\hline & $\begin{array}{l}\text { Eine gesatzte Ordnung in dem hier gemeinten rein } \\
\text { empirischen Sinn ist - wie hier nur ganz provisorisch } \\
\text { definiert sei - entweder 1. Eine einseitige, im rationalen } \\
\text { Grenzfall: ausdrückliche, Aufforderung von Menschen an } \\
\text { andere Menschen oder 2. Eine, Im Grenzfall: ausdrückliche, } \\
\text { beiderseitige Erklärung von Menschen zueinander, mit dem } \\
\text { subjektiv gemeinten Inhalt: dass eine bestimmte Art von } \\
\text { Handeln in Aussicht gestellt oder erwartet werde (MWG } \\
\text { 1/12, p. 408). }\end{array}$ \\
\hline & TRECHO TRADUZIDO \\
\hline & $\begin{array}{l}\text { "Uma ordem estatuída no sentido meramente empírico ao } \\
\text { qual se alude aqui - como é aqui apenas provisoriamente } \\
\text { definido - ou } 1 \text {. no caso limite unilateral racional: uma } \\
\text { demanda unilateral de certas pessoas sobre outras ou } 2 \text {. no } \\
\text { caso limite: uma explicação explícita bilateral mútua sobre o } \\
\text { conteúdo (teor) do sentido subjetivamente intencionado, que } \\
\text { um determinado tipo de ação está sendo prometido ou } \\
\text { esperado" (tradução da autora). }\end{array}$ \\
\hline
\end{tabular}

Fonte: própria autora.

A ordem estabelecida é a formalização de uma ação regular. Afinal, é a partir dos pressupostos normativos e condutas típicas da ordem que os agentes orientam subjetivamente as suas próprias ações — sejam esses pressupostos definidos através de uma demanda unilateral de poucos sobre o conjunto de integrantes da ordem ou seja pela exposição bilateral do conteúdo de sentido de uma ação. Assim, nesse contexto, quando o conteúdo de sentido da orientação individual da ação corresponde ao conteúdo de sentido da ordem, tal ordem estabelecida é considerada "válida” empiricamente. Em outras palavras, a ordem é validada, na prática, quando a ação real (objetiva) dos associados corresponde à ação proposta subjetivamente em orientação ao 
conteúdo de sentido da ordem.

Em caso limite-racional ideal de análise, aqueles que agem de maneira racional referente a fins calculam subjetivamente as probabilidades objetivas da ação em uma dada ordem. Por isso, comumente as ações racionais de fins orientadas por uma ordem válida são adequadamente causadas e estão assentadas sob o cálculo de possibilidade objetiva média das ações. ${ }^{6}$ As probabilidades objetivas servem, aqui, como base cognitiva para as expectativas. Nesse cenário, quanto mais assentadas sobre normas e regras legalizadas e sobre racionalidade de fins, tanto maior a estabilidade da ordem. Isso porque a legalidade da ordem é subjetivamente revestida de sentido para os atores, e, portanto, é “vinculante”. Assim, quando as ordens são validadas unicamente pela expectativa do comportamento alheio elas formam casos instáveis.

Mas há casos dissonantes em que o indivíduo orienta subjetivamente sua ação segundo sua interpretação pessoal do conteúdo de sen-

\footnotetext{
${ }^{6}$ A correspondência entre conteúdo de sentido da ação individual e conteúdo de sentido da ordem advém da possibilidade objetiva [objective Möglichkeit]. John Stuart Mill, o inaugurador da tese da possibilidade objetiva, a compreendia como o equilíbrio entre os fatores que favorecem determinado desfecho de um fenômeno e os fatores que evitam tal desfecho. Mas é com a teoria da adequação causal, de Von Kries, que Weber dialoga, especificamente em Estudos críticos sobre a lógica das ciências da cultura [Kritische Studien auf dem Gebiet der kulturwissenschaftlichen Logik]. Von Kries transportou o método causalista das Ciências Naturais para as Ciências Sociais, pois defendia que havia conhecimento nomológico também na possibilidade objetiva das conexões causais na análise causal na jurídica: a adequação causal. Na prática, de acordo com Weber (1906), o pesquisador deve procurar compreender o motivo (intenção) da ação dos atores, e, então, verificar se esse motivo efetivamente levou às consequências (efeito) em questão. É necessário pensar contrafactualmente, imaginar como se desenvolveria um determinado acontecimento se sua causa fosse outra ou ausente e quais seriam as divergências possíveis em cursos de ações esperados. Isso é possível graças a nosso conhecimento probabilístico e a nossa capacidade de fabricar possibilidades objetivas e factíveis para os fenômenos. A possibilidade objetiva, sem síntese, considera ao mesmo tempo a média das ações e a causação adequada.
} 
tido da ordem. Há casos em que, por outro lado, o indivíduo orienta sua ação segundo múltiplas ordens — ordens que podem, inclusive, se contradizer e coexistir como empiricamente válidas. Ainda, há situações em que o associado reconhece a ordem social em seu conteúdo de sentido válido empiricamente, mas opta por infringi-la conscientemente - como um indivíduo que decide roubar ou matar outrem em sigilo (WEBER, MWG 1/12, p. 409). Ao infringir a ordem estabelecida, segundo Weber (MWG 1/12, p. 408-409), o agente ratifica a existência de sua validade empírica por duas vias — ambas identificáveis pelo pesquisador. A primeira via (via suposta) indica que os indivíduos infringem a ordem por contar com a expectativa de que os demais atores orientarão de suas ações “como se” tomassem o conteúdo de sentido da ordem como guia da ação. A segunda via (via calculável) indica que os indivíduos infringem a ordem porque esperam uma ação específica dos demais associados haja vista a média provável das ações. A segunda situação indica que o sujeito calculou objetivamente sua ação em função da causação adequada das demais ações.

Em tese, por fim, é possível afirmar, com vistas ao formulado por Weber (MWG 1/12, p. 408-409), que a validade empírica de uma ordem racionalmente instituída com relação a fins refere-se a: a) expectativa de que os demais atores se comportarão "como se" tomassem o conteúdo de sentido da ordem estabelecida como guia de suas ações (expectativa); b) possibilidade objetiva de manter essa expectativa tendo em vista a existência um comportamento humano médio (cálculo objetivo); ou c) orientação coletiva das ações segundo o conteúdo de sentido comum (conexão com a relação em sociedade).

Acontece que mesmo ordens empiricamente válidas, instituídas com relação a fins, podem desaparecer. Isso porque as ordens são 
constituídas de uma contínua escala de transições de relações e ações. Para que uma ordem estabelecida persista é necessário que a relação em sociedade perdure em relevância prática. Além disso, para que uma relação em sociedade exista, é necessário que os atores ajustem mutuamente suas ações de acordo com o conteúdo de sentido comum. Logo, caso as ações em sociedade não estejam orientadas por um conteúdo de sentido comum, e, em consequência, as relações em sociedade não perdurem, também a ordem estabelecida deixa de existir.

Em relações em comunidade por acordo, por outro lado, o processo é mais complexo e de intrincada compreensão. Schluchter (2014), por exemplo, defende que em relações em comunidade por acordo vigora um tipo específico de ordem, a "Ordem pressuposta" [unterstellte Ordnung]:

trata-se, ao contrário, de uma suposição que, na falta de uma ordem estatuída [estabelecida], seja por acordo, seja por imposição, com sua correspondente forma de organização, seja uma instituição, seja uma união racional [de fins], permite ao ator uma ação coordenada (SCHLUCHTER, 2014, p. 208).

Isso significa que as ações podem ser regulares mesmo na ausência de um "estatuto" formalizado. Afinal, seus participantes orientam-se pela possibilidade objetiva de que as expectativas de comportamento sejam válidas. Assim, tomam os acordos subentendidos como normas obrigatórias, máximas para a ação.

A tese de Schluchter (2014) é uma leitura possível, uma hipótese sustentável. No entanto, ao adentrarmos ao texto de Weber propriamente dito, não encontramos o termo unterstellte Ordnung, quiçá uma menção a existência de ordem em ações em comunidade por acordo regulares. Afinal, ao longo do capítulo 6 de Kategorien, Weber somente alude à ordem de maneira indireta ao afirmar que "Es gibt Komplexe 
von Gemeinschaftshandeln, welche ohne eine zweckrational vereinbarte Ordnung dennoch 1. Em Effekt so ablaufen, als ob eine solche statt gefunden hätte, und bei welchen 2. Dieser spezifische Effekt durch die Art der Sinnbezogenheit des Handelns der Einzelnen mitbestimmt ist”. ${ }^{7}$

Se efetivamente há uma ordem no seio das relações em comunidade por acordo, não está claro no texto. Podemos afirmar tão somente que em Kategorien as relações em comunidade por acordo são orientadas por complexos de sentido que não possuem um acordo firmado, embora funcionem “como se” tal acordo existisse. O intercâmbio do dinheiro, por exemplo, refere-se em seu sentido à expectativa da ação dos demais agentes que intercambiam dinheiro (como comerciantes, compradores, entre outros). Ainda que não haja uma ordem firmada, os integrantes dessa relação orientam-se segundo a expectativa da aceitação comum do dinheiro.

Em vista disso nos parece factível afirmar que em relações em comunidade por acordo, apesar da ausência da ordem, há complexos de sentido comuns que coordenam as ações. Não rejeitamos completamente a posição de Schluchter (2014), embora a aceitemos somente como uma hipótese em meio a diversas interpretações possíveis. Mas, dada a falta de fundamentação exegética desta hipótese, nos manteremos fiéis ao exposto no texto e aceitaremos, para fins didáticos de exposição, a inexistência da ordem em relações em comunidade por acordo. O Quadro 2 sistematiza a teoria das ordens de 1913:

\footnotetext{
7 “Há complexos de ação em comunidade que, na ausência de uma ordem firmada de maneira racional com referência a fins 1. pode operar como se esse acordo realmente existisse e 2 . cujo efeito está codeterminado pelo tipo de referência de sentido da ação dos indivíduos” (tradução da autora).
} 
Quadro 2 - Sistematização da tipologia das ações, relações, organizações e ordens de Kategorien.

\begin{tabular}{|c|c|c|}
\hline \multicolumn{3}{|c|}{ AÇÃO EM COMUNIDADE } \\
\hline Por acordo & \multicolumn{2}{|c|}{ Em sociedade } \\
\hline & \multicolumn{2}{|c|}{ Em sociedade } \\
\hline \multirow{2}{*}{$\begin{array}{c}\text { Em comunidade por } \\
\text { acordo }\end{array}$} & - & União de fins \\
\cline { 2 - 3 } & ORDEM \\
\hline \multirow{3}{*}{-} & Estabelecida \\
\cline { 2 - 3 } & ORposição & $\begin{array}{c}\text { Esclarecimento } \\
\text { mútuo }\end{array}$ \\
\hline & Instituição & - \\
\hline Organização & ORGÃ̃̃ \\
\hline
\end{tabular}

Fonte: própria autora, com base em Weber (1913).

No caso da ação em sociedade, quando regulada pela ordem estabelecida, pode formar uma instituição [Anstalt] — uma relação em sociedade regulamentada formalmente por um estatuto que possui associação involuntária. Já em uma ação em comunidade por acordo, somente se assumirmos a assertividade da tese de Schluchter (2014), é possível afirmar que há a formação da organização [Verband] — uma relação em comunidade baseada em um acordo simples - em consonância com seus complexos de sentido. ${ }^{8}$

\section{A Ordem Social em Grundbegriffe}

Na segunda parte de Grundbegriffe (Conceito de Ação Social) Weber conceitua muitas das noções fundamentais de sua Sociologia Com-

\footnotetext{
${ }^{8}$ As organizações sociais são um capítulo à parte na teoria da Max Weber e merecem um tratamento cuidadoso. De antemão, apenas para fins de elucidação, esclarecemos que no texto de 1913 ele conceitua a organização como a regulamentação formal da ação. São 3 os tipos: organização [Verband], a instituição [Anstalt] e a união de fins [Zweckverein].
} 
preensiva. Especificamente após definir a relação social (§ 3) ele passa ao tema das ordens sociais ( $\S 5, \S 6$ e §7) pois, assim, consegue fazer o link entre ações mutuamente ajustadas em seu conteúdo de sentido (relações sociais) e formas mais amplas de linhas de ação (ordens sociais).

Nos parágrafos 5, 6 e 7 (e suas respectivas notas), Weber firma dois elementos que compõem a ordem legítima: o cognitivo (representação) e o moral-normativo (vigência e legitimidade). ${ }^{9}$ O elemento cognitivo alude a existência da ordem stricto sensu no plano da representação. É essa representação o que permeia a legitimidade e a vigência. O elemento moral-normativo, por sua vez, diz respeito ao sentimento de dever de cumprimento da ordem. A ordem é introjetada pelo próprio agente e tomada, assim, como uma máxima para a ação.

A imagem mental da existência de uma ordem [Ordnung] é o que garante externa e internamente a regularidade das ações socais dos seus participantes. Nas palavras de Weber "Handeln, insbesondre soziales Handeln und wiederum insbesondre eine soziale Beziehung, können von seiten der Beteiligten an der Vorstellung vom Bestehen einer legitimen Ordnung orientiert werden"10 (MWG 1/23, p. 21). Na prática, os indivíduos aceitam a representação [Vorstellung] de uma ordem social como referência de suas ações. Essa ordem não é, portanto, concreta e palpável. Ela é algo que está na mente de inúmeros agentes.

\footnotetext{
${ }^{9}$ Merquior (1990) propõe a decomposição do conceito de ordem legítima em validade, convicção coletiva e probabilidade. Não utilizo essa subdivisão pois ela desconsidera o sentimento interno de dever de cumprimento da ordem (produzido pelo próprio agente), conforme explicitarei nesta seção.

10 “Toda ação, especialmente a ação social e, por sua vez, particularmente a relação social, podem ser orientadas, pelo lado dos participantes, pela representação da existência de uma ordem legítima” (WEBER, 1921, p. 19).
} 
A ordem seria, sob essa perspectiva, um conteúdo de sentido que orienta a média das ações no interior de uma relação, sendo que essas ações lhe servem de material que confere sustentação, fundamentação e substância. Weber (MWG 1/23, p. 22) fala em "média das ações" pois ele considera a quantidade de pessoas que se orientam pela ordem um fator importante. Afinal, para que uma ordem se mantenha estável é necessário que uma quantidade significativa de pessoas se oriente por ela.

A vigência de uma ordem indica a probabilidade de que as ações se orientem, na prática, pelo conteúdo de sentido da relação. Isso é, que as ações adotem tal conteúdo de sentido como modelo moralmente obrigatório de comportamento. Um exemplo prático é o de uma recepcionista que chega antecipadamente todos os dias ao escritório, seu local de trabalho. O costume de acordar rotineiramente no mesmo horário e habitualmente ir ao escritório é, nesse sentido, uma explicação possível. O interesse pessoal por convenientemente ser um funcionário exemplar também pode ser outra justificativa. Mas ambas as hipóteses desconsideram a ação racionalmente referida aos valores. Não é apenas o hábito, nem somente a situação de interesse. Essa ação pode ser explicada, ainda, através do sentimento de dever. ${ }^{11}$

\footnotetext{
${ }^{11}$ Weber combina o reconhecimento do dever e dos motivos utilitários, ambos, como cerne da sustentação da vigência da ordem. É justamente esse entrecruzamento entre vigência por sanções e vigência por (suposta) compulsão, intitulada por Merquior (1990) de "bifurcação conceitual obscurecida”, o cerne de inúmeras críticas à teoria de Weber. De acordo com Merquior, Weber insistiu em expulsar motivações claramente humanas (como as emoções e os impulsos íntimos mais irracionais) por considerá-las tipos heurísticos menos racionalizados. Isso fez com que, segundo essa interpretação, Weber se atrelasse em demasia à abordagem racionalista-utilitarista. Todavia, Weber não retoma aqui a ação (irracional) afetiva nem a ação utilitária. Ele reconhece, antes, que a vigência de uma ordem advém preferencialmente da referência (racional) aos valores. Os motivos utilitários ficam, na verdade, em segundo plano. Logo, nós não reconhecemos, como Merquior (1990), o apego excessivo de Weber ao utilitarismo.
} 
A vigência de uma ordem pode ser reconhecida como legítima pelos agentes por conta $a$ ) da tradição, $b$ ) da crença afetiva, $c$ ) da crença racional referente a valores, $d$ ) da legalidade de um estatuto (seja essa legalidade legitimada por acordo ou por imposição). É importante ressaltar que Weber discutiu essa questão em maior grau de complexidade no capítulo VII (Sociologia do Direito) e no capítulo IX (Sociologia da Dominação) de $W u G$. Nos ateremos, aqui, estritamente ao texto Grundbegriffe.

a) Vigência legítima atribuída pela tradição. A tradição intenta > conservar a ordem vigente por meio da manutenção das formas $>$ habituais de comportamento (do que sempre foi assim e terá de $>$ continuar a ser). Nesse contexto a tradição é vista como algo > sagrado e intocável. Sua origem remonta ao medo da mágica, vista > como prática negativa, o qual fortaleceu a inibição psíquica à > mudança.

b) Vigência legítima atribuída pela crença afetiva-emocional. Essa é a > emoção ativada pelo “novo” revelado como modelo. Nessa passagem > Weber (MWG 1/23, p. 26/27) alude aos oráculos proféticos e às $>$ revelações proféticas que vigoraram em épocas de tradicionalismo $>$ rigoroso. Ambos foram criados conscientemente para ser uma ordem $>$ sagrada genuinamente nova, apesar de serem tratadas como práticas > antigas reafloradas.

c) Vigência legítima atribuída pela crença racional referente a > valores. O exemplo-mor dado por Weber (MWG 1/23, p. 26) é o $>$ direito natural. Em contraposição aos direitos racionalmente > instituídos com referência a fins (como o direito esta- 
tuído), o > direito natural se baseia em pretensões ideais reconhecidas como > absolutamente válidas.

d) Vigência legítima atribuída por acordo (legalizada). Mesmo nos casos > em que a ordem é pactuada, se ela não advier de um acordo unânime, > há imposição. Aqueles que destoam da vontade da maioria estão, > nessas situações, sob imposição da vontade alheia. É possível que, > ainda, em outra situação, minorias de imponham sob a vontade da $>$ maioria, especialmente por serem mais intensas e destemidas. > Assim, é possível que os opositores passem, pouco a pouco, a > legitimar essa vigência.

e) Vigência legítima atribuída por imposição (legalizada). Uma ordem é > imposta quando não advém de um acordo livre entre todos os seus $>$ participantes (como o caso do voto majoritário). Uma consequência > possível e comum é a submissão. Os indivíduos tendem a crer nessa > autoridade imposta como legal e legítima, e, por vezes podem, > inclusive, tratá-la como tradição. Um exemplo é o poder > governamental que apanha para si a imposição legítima de novas > ordens.

Conforme é possível perceber, os limites entre vigência (factual) e legitimidade (normativa) não são completamente delimitados em Grundbegriffe. Em alguns momentos parece que Weber os trata como conceitos fluidos, interdependentes, complementares, e, inclusive, semelhantes. Afinal, as ordens são legítimas (consideradas como máximas) quando possuem vigência (quando possuem grande probabilidade de convicção em uma legitimidade) e ordens são vigentes enquanto consideradas legítimas. Daí o conceito de "vigência legítima” amplamente desenvolvido no §7. 
É importante dizer que Weber (MWG 1/23, p. 24-25) dedicou grande parte do seu esforço em explicar os casos de ordens impostas consideradas legítimas por sua legalidade. Isso dado que elas perduram nas sociedades contemporâneas, especialmente através de uma constituição. A constituição de uma ordem indica os limites, os assuntos e as condições através das quais tanto os membros quanto o quadro administrativo de uma ordem se submetem a uma nova imposição. ${ }^{12}$

Mesmo nos casos em que se descumpre intencionalmente a constituição de uma ordem legal, reafirma-se a sua vigência. Um ladrão que rouba uma casa quando os moradores não se encontram, ao tentar ocultar o seu crime, reafirma de forma racional referente a fins a vigência da ordem jurídica que criminaliza o roubo. Esse é um casolimite em que o agente tem que ocultar sua violação. Mas há casos de menor grau de transgressão em que os agentes tentam, de boa-fé, apresentar uma ordem alternativa como legítima, por exemplo.

Por outro lado, quando a orientação média das ações passa a ser de violação do conteúdo de sentido, a ordem passa a ter vigência limitada. É possível que com isso, caso a violação torne-se a regra, a vigência deixe de existir. Mas é necessário dizer que essas transições são fluidas na realidade pois é possível, inclusive, que vigências contraditórias entre si vigorem na mesma ordem. Há outros casos em que, em contraposição, o sentido da ordem é interpretado de inúmeras formas por inúmeras pessoas fazendo em que haja, respectivamente, inúmeras vigências. Esses casos são mais complexos para serem analisados sociologicamente. Afinal, é difícil reconhecer a vigência paralela de ordens contraditórias entre si — fenômeno especialmente elucidável

\footnotetext{
${ }^{12}$ Esse debate está assentado em Lassalle (2002). Ele entendia a constituição, em seu sentido sociológico, como os fatores reais de poder que perduram em uma comunidade, um o reflexo das forças sociais que estruturam o poder.
} 
através do exemplo da recepcionista do escritório, desenvolvido na seção anterior.

Ordens legítimas são ordens com grande probabilidade coletiva de conviç̧ão em sua validade e de aceitação de sua autoridade. Por isso, quando as ordens não têm como base o sentimento de dever ou um padrão ético considerado moralmente bom — ordens regidas pelo interesse externo (como o mercado) — não podem ser consideradas legítimas. Resumidamente, a legitimidade de uma ordem ${ }^{13}$ pode ser garantida por duas vias: 1) através da atitude interna, sendo ela $a$ ) por entrega sentimental (afetiva), b) pela crença em sua vigência absoluta (racional referente a valores), c) pela crença nos seus bens de salvação religiosa (racional referente a valores) ou 2) através dos interesses pessoais externos e expectativas de determinado gênero, sendo eles a) uma convenção habitual (tradicional) ou b) um direito (racional referente a valores).

A legitimidade interna de uma ordem pode ser garantida por um padrão ético considerado moralmente bom pelo próprio agente individual. Nesses casos, mesmo que não haja uma garantia externa (como a coação), a representação ética influencia profundamente uma ação inicial, e, ao mesmo tempo, suas consequências não transcendem às ações alheias. Ainda, há ordens que possuem, concomitantemente, legitimidade interna e externa. Esse é o caso da proibição do assassinato.

\footnotetext{
${ }^{13} \mathrm{O}$ debate sobre a legitimidade no seio da teoria social moderna remonta ao iluminismo. Autores como Maquiavel, Hobbes, Locke, Montesquieu, Rousseau, Voltaire, Kant, Hume, entre outros desenvolveram abordagens efetivamente científicas para questões centrais e tangenciais da legitimidade. Mas é Max Weber o responsável por fundar uma discussão estritamente sociológica para o tema. Sua teoria da legitimidade integra os textos de Teoria Política de caráter mais empírico (como o capítulo 8 de $W u G$ intitulado comunidades políticas e o capítulo 9, Sociologia da Dominação) os textos de Teoria Política de conceituação mais genérica (como o capítulo 3 de $W u G$ ) e seu texto sobre a Sociologia Compreensiva de 1921 (tratado na presente pesquisa como Grundbegriffe), de caráter conceitual (MERQUIOR, 1990).
} 
Ao mesmo tempo um agente pode orientar-se pela máxima religiosa "não matarás” e pelo ordenamento jurídico que proíbe o assassinato de qualquer espécie. ${ }^{14}$

Weber (MWG 1/23, p. 24-25) dedicou suas discussões especialmente às ordens legitimadas externamente, como a convenção e o direito, pois elas são reconhecidas pela expectativa de consequências externas, e não por meros comportamentos internos. Segundo Merquior (1990), essa legitimidade resulta da confiança que os governados depositam nos governantes. Ela depende das formas de poder validadas na cultura política.

Em síntese, podemos definir a ordem legítima como um conjunto de normas, deveres e responsabilidades [Vorbindlichkeit] considerados “máximas obrigatórias para as ações” [Maximen] e modelos indicáveis [Vorbildlichkeit] para as relações, das quais decorrem regularidades (ESSER, 2000). Com essa representação de máximas obrigatórias os atores atribuem sentido e significado à ordem e, ao mesmo tempo, orientam suas ações por ela conferindo-lhe, assim, substância.

\footnotetext{
${ }^{14}$ Mesmo essa robusta formulação de Weber sobre as ordens sofre com inexoráveis críticas. Em semelhança com Merquior (1990), Grafstein (1981) afirma que, ao intentar compreender o motivo, a crença e o significado das ações regulares Weber recorre a uma abordagem psicológica. Para tanto, ele utiliza o recurso realista da criação de tipos ideais de motivações de comportamento. Seu erro consiste justamente, segundo Grafstein, em explicar a ordem de forma tautológica e circular, recorrendo sempre à mesma abordagem psicológico-realista. Segundo esse argumento, Weber compreenderia o processo social de formação de uma ordem como a projeção de significados em seus participantes, os quais, por suas vezes, são conduzidos a agir motivados por esse complexo de sentido. Ainda assim, mesmo com essa incisiva crítica, Grafstein (1981) defende que é necessário partir da teoria weberiana das ordens para fundar o conceito de legitimidade por três motivos. Primeiro, o significado pretendido não é identificado com o significado consciente do ator. Segundo, o significado pretendido associado ao tipo ideal não é igualado ao significado psicológico real ou a qualquer média estatística de significados reais. Terceiro, os significados pretendidos hipotéticos estão relacionados a padrões hipotéticos de comportamento em fundamentos lógicos a priori.
} 
Isso evidencia a força das ordens sociais legítimas que combinam Vorbildlichkeit e Verbindlichkeit.

Isso posto, é possível defender a tese de que as ordens dependem intrinsecamente das ações e relações sociais. As ordens não são possíveis sem ambos os elementos. A vinculação inversa também existe — de influência da ordem sobre as ações e relações —, mas em nível mais fraco. Acontece que as ordens existem pelas ações e relações, mas as ações podem se desenvolver sem as ordens. Para utilizar a terminologia definida no capítulo 3, ambas as dimensões possuem propriedades causais. Mas as ordens possuem propriedades emergentes fracas ${ }^{15}$ e as ações sociais são capazes de estabelecer uma causalidade ascendente.

Schluchter (2014) reitera a nossa posição ao afirmar que em Weber as relações objetivas possuem caráter causal que precisam necessariamente, remeter-se às ações. Os fenômenos coletivos são, sob essa perspectiva, chances de que as ações sociais se desenvolvam de uma determinada maneira. Ainda assim, Weber reconhece a importância de desenvolver uma linguagem conceitual específica para os fenômenos de nível "macro", especialmente para os tipos de ordens, conforme exposto doravante.

\section{Os tipos de ordem}

Em Grundbegriffe Weber desenvolveu um aparato conceitual distinto e mais complexo do que o de Kategorien (SCHLUCHTER, 2014), embora com conteúdo semelhante (SCHLUCHTER, 2005). Isso fica especialmente visível quando analisamos a tipologia de ordem. Weber criou uma robusta tipologia das ordens ao incluir as re-

\footnotetext{
${ }^{15}$ Albert (2016) define a emergência fraca como a propriedade explicativa da macroestrutuea redutível ao nível micro.
} 
presentações e garantias de vigência e legitimidade. Ele atrelou tais questões preliminares sobre a natureza da ordem à sua teoria precedente das ações e relações. Com isso, o autor pôde substituir sua tipologia inicial (ordem estabelecida, e, segundo Schluchter, ordem pressuposta) por uma formulação triádica mais abrangente: a ordem jurídica, ordem econômica e ordem convencional.

Weber desenvolveu um modelo quádruplo da ação social (ação tradicional, ação afetiva, ação racional com referência a valores e ação racional com referência a fins). Também as suas reflexões acerca das características das ordens, especificamente da vigência, seguem esse modelo. A vigência pode ser atribuída pela tradição, pela crença afetiva-emocional, pela crença racional referente a valores e pelo cálculo de fins (seja por acordo ou por imposição). A legitimidade, por outro lado, pode ser garantida unicamente pela convenção, pela entrega sentimental, pela crença (na vigência absoluta, nos bens de salvação ou no direito), mas não pode ser garantida de forma racional referente a fins/por interesse. Isso demonstra que o modelo de ordem de Weber não persegue completamente o seu modelo quádruplo. O Quadro 3 organiza essas informações. 
Quadro 3 - Ação, relação, ordens, vigência e

legitimidade em Grundbegriffe.

\begin{tabular}{|c|c|c|c|c|c|}
\hline \multicolumn{6}{|c|}{ AÇÃO SOCIAL } \\
\hline $\begin{array}{l}\text { Tradi- } \\
\text { cional }\end{array}$ & Afetiva & \multicolumn{3}{|c|}{ Racional com relação a valores } & $\begin{array}{l}\text { Racional } \\
\text { com } \\
\text { relação a } \\
\text { fins }\end{array}$ \\
\hline \multicolumn{6}{|c|}{ RELAÇÃO SOCIAL (PERENE) } \\
\hline Costume & - & \multicolumn{3}{|c|}{ Uso } & $\begin{array}{l}\text { Situação } \\
\text { de } \\
\text { interesse }\end{array}$ \\
\hline \multicolumn{6}{|c|}{ ORDENS SOCIAIS } \\
\hline $\begin{array}{l}\text { Conven- } \\
\text { cional }\end{array}$ & - & \multicolumn{3}{|c|}{ Jurídica } & $\begin{array}{l}\text { Econô- } \\
\text { mica }\end{array}$ \\
\hline \multicolumn{6}{|c|}{ VIGÊNCIA DAS ORDENS (FACTUAL) } \\
\hline Tradição & $\begin{array}{c}\text { Crença } \\
\text { afetiva- } \\
\text { emociona } \\
\text { l }\end{array}$ & \multicolumn{3}{|c|}{$\begin{array}{c}\text { Crença racional referente a } \\
\text { valores }\end{array}$} & $\begin{array}{l}\text { Cálculo } \\
\text { de fins }\end{array}$ \\
\hline \multicolumn{6}{|c|}{ LEGITIMIDADE DAS ORDENS (NORMATIVO) } \\
\hline Externa & \multicolumn{3}{|c|}{ Interna } & Externa & - \\
\hline $\begin{array}{l}\text { Conven- } \\
\text { ção social } \\
\text { (possibili } \\
\text { dade de } \\
\text { boicote) }\end{array}$ & $\begin{array}{l}\text { Entrega } \\
\text { senti- } \\
\text { mental }\end{array}$ & $\begin{array}{c}\text { Crença } \\
\text { na } \\
\text { vigência } \\
\text { absoluta }\end{array}$ & $\begin{array}{l}\text { Crença } \\
\text { nos bens } \\
\text { de } \\
\text { salvação }\end{array}$ & $\begin{array}{c}\text { Crença } \\
\text { no } \\
\text { direito }\end{array}$ & - \\
\hline
\end{tabular}

Fonte: própria autora, com base em Weber (1921).

Quando Weber (1921) elabora os tipos de ordens sociais ele retoma, sob nossa perspectiva, os modelos de relações sociais perenes: ${ }^{16}$ o uso, o costume e a situação de interesses, os quais, por suas vezes, estão vinculados respectivamente a ação racional com referência a valores, ação tradicional e ação racional com referência a fins. Assim,

\footnotetext{
${ }^{16}$ Há conteúdos de sentido que são perenes e expressos em forma de máximas. Quanto mais as ações se orientem de maneira racional (seja por fins ou por valores) nesse contexto tanto mais os participantes podem esperar que, em média, seus parceiros orientarão suas ações segundo essas “máximas”. Por isso, tendo em vista as parcelas de irracionalidade de ambas as ações, é difícil que relações afetivas ou eróticas se tornem perenes.
} 
o autor consegue associar cada tipo de ordem a um tipo respectivo de relação duradoura. À relação de uso, Weber filia a ordem jurídica. Ao costume, a ordem convencional. E à situação de interesses, a ordem econômica.

A ordem convencional, especificamente, baseia-se no costume e no hábito vigentes. Sua legitimidade está garantida pela probabilidade média da reprovação de hábitos discordantes. ${ }^{17}$ Os hábitos discordantes costumam ser castigados, por meio do boicote social, desaprovação ou punição, com maior rigor pelos membros comuns da ordem do que a juridização o é por seu quadro especializado. Por isso, tento em vista a internalização dos hábitos comuns de ação, o boicote social provou ser um instrumento eficaz de instauração da legitimidade.

Mesmo com essa comprovação de eficácia, há casos-limite de transição. A progressiva utilização do boicote formal e organizado pode sinalizar a transição de uma ordem convencional para a jurídica. A ordem jurídica, ao contrário da convencional, baseia-se em regras estabelecidas. Sua legitimidade advém ou da crença na superioridade formal da lei ou do possível uso de coerção (seja ela física ou psíquica) por parte de um quadro especializado e ocupado em castigar a violação da ordem (como os juízes, procuradores, funcionários administrativos, executores, entre outros). Com isso, a ordem jurídica costuma “forçar” as ações ao cumprimento do que está regulamentado.

Para que o quadro coativo exista e atue não é necessária a instituição de uma instância judiciária. À vista disso, mesmo formações sociais não industriais, não burocráticas e não contemporâneas podem apresentar um quadro coativo - ainda que ele esteja no limite do que

\footnotetext{
${ }^{17}$ Nesse ponto a perspectiva de Stammler (1896) está equivocada. Ele entende a convenção como uma submissão voluntária ao costume. Mas ela é mais complexa que isso, pois, na verdade, a convenção se institui como uma exigência ao indivíduo, uma máxima, um mandamento (WEBER, 1921).
} 
Weber (1921) entenda por coação jurídica. Esse é o caso, por exemplo, de um grupo indígena que possui um quadro seleto de pessoas encarregadas a julgar casos de roubo ou assassinato ocorrido no interior do grupo.

Grafstein (19821) afirma que a preocupação central de Weber ao desenvolver a ordem jurídica são as populações heterônomas que não possuem muitos interesses comuns. São esses tipos de organização que precisam majoritariamente de uma autoridade legal de mando. Essa ideia se aproxima da abordagem de Luhmann (1975), autor que também reconhece que as formações sociais modernas não se apoiam na unidade moral ou em acordos unânimes, mas que, antes, pautam-se em procedimentos legais pré-estabelecidos.

É complexo tratar da legitimidade da ordem jurídica enquanto um cumprimento voluntário e intimamente motivado porque ela costuma dispor de um aparato coativo. Seu sistema é definido pela coerção àqueles que não cumprem as pré-disposições da ordem. Por via de regra, a existência de uma ordem legal dificulta a efetiva crença subjetiva no valor da legitimidade legal. Logo, os sentidos imputados a ordem podem ser os mais diversos

No §6 Weber tipificou oficialmente ordens convencional e jurídica. Em nenhuma passagem de Grundbegriffe ele cita a existência da ordem econômica propriamente dita. No §4 ele aventa a possibilidade de que as ações sociais tornem-se regulares através da "situação de interesses” (uma das três características das relações sociais), especialmente por meio de expectativas de ações puramente racionais referente a fins (assim como as ações puramente econômicas). Em situações de interesse os agentes avaliam subjetivamente, através do conhecimento prévio das ações comuns dos demais agentes, meios pelos quais poderão alcançar seus interesses. 
Ainda que ele não tenha formalmente criado a ordem orientada por interesse em Grundbegriffe, em Wirtschaft und Gesellschaft (especificamente no Capítulo 1 da Primeira Parte/Primeiro Volume e no Capítulo 1 da Segunda Parte/Segundo Volume) ele a desenvolveu sistematicamente. Para os fins de análise deste estudo não nos interessa o conteúdo da discussão desenvolvida no Capítulo 1 da Segunda Parte de $W u G$. Mas esse fato nos é útil para afirmar que Weber reconhece a existência de uma ordem econômica fora de Grundbegriffe. Por isso, é possível questionar se Weber não contempla formalmente a ordem econômica em Grundbegriffe intencionalmente, mesmo que em outros textos de $W u G$ ele a tenha desenvolvido em profundidade. É possível questionar, inclusive, se em sua produção madura ele realmente considerada possível que interesses instaurassem ordens sociais

Resumidamente, conforme sistematizado no Quadro 4, a ordem convencional é garantida pela aprovação cotidiana dos costumes, enquanto a ordem jurídica está assegurada por um quadro coativo especializado em seu cumprimento. A situação de interesses, por sua vez, se a considerarmos um tipo de ordem econômica de Grundbegriffe, é garantida por interesses pessoais. Todas essas ordens tendem a ser conservadas ao longo do tempo e tornarem-se estáveis. Especialmente a ordem convencional, por conta da reprovação, do boicote e do hábito, tende a ser a mais contínua (isso é, mais persistente no tempo). Mas há um tipo de orientação ainda mais estável, baseada na crença de sua legitimidade (relação de uso): a orientação racional por valores. Quando a ordem é orientada exclusivamente de forma racional referente a fins, ela é mutável pois depende do êxito pessoal, de uma instrumentabilidade calculável. Mas, mesmo com a tendência de permanência e manutenção, Weber reconhece a possibilidade de transformação e de completa dissolução das ordens. 
Quadro 4 - Mecanismos de sanção das ordens.

\begin{tabular}{|c|c|c|}
\hline \multirow{2}{*}{ ORDEM } & \multicolumn{2}{|c|}{ MECANISMOS DE SANÇÃO } \\
\cline { 2 - 3 } & $\begin{array}{c}\text { Conteúdo/ } \\
\text { expectativa }\end{array}$ & Agentes \\
\hline Convencional & Reprovação & $\begin{array}{c}\text { Indivíduos em geral } \\
\text { informal }\end{array}$ \\
\hline Jurídica & Coação & $\begin{array}{c}\text { Quadro de pessoas } \\
\text { organizado }\end{array}$ \\
\hline Econômica & Interesse & Mercado \\
\hline
\end{tabular}

Fonte: própria autora, com base em Weber (MWG 1/23).

Em consonância com a reflexão de Schluchter (2014), a ordem econômica é uma máxima instrumental e não normativa (regra de). Já as máximas convencional e jurídica são normativas (regra para). Especialmente no caso das ordens convencional e jurídica é possível encontrar elementos morais que auxiliam na normatização (e normalização) das regras. Dentre esses elementos podemos destacar o sentimento de dever.

Como podemos verificar, nem em 1913 e nem em 1921 Weber contempla toda a tipologia da ação em sua teoria da ordem. Em Kategorien Weber leva em consideração (excluindo a hipótese Schluchter) exclusivamente a ordem estabelecida derivada da ação em sociedade. A ação por acordo, ainda que possua uma formalização de linhas de ação implícita, ficou à deriva no desenvolvimento formal de uma ordem. Já em Grundbegriffe Weber concebe a ordem jurídica advinda da ação racional com referência a valores e a ordem convencional derivada da ação tradicional. Se aceitarmos a situação de interesses como uma ordem, há também a ordem econômica derivada da ação de fins. Todavia, nesse sentido, a sua ação afetiva não está contemplada. Os motivos dessa exclusão não sabemos ao certo. Mas podemos afirmar que outrora Weber desenvolveu reflexões acerca da possibilidade da 
formação de uma ordem social via ação afetiva.

Weber não inseriu a ordem dos afetos em seu tratado sobre a Sociologia de 1921. Hoje não sabemos se intencionalmente ou não. Mas em textos anteriores, como aqueles sobre a dominação carismática (textos pré-Guerra: Carismatismo, Transformação do carisma, Manutenção do carisma, Estado e hierocracia; texto pós-Guerra: Dominação Carismática), como bem destaca Lepsius (2017), Weber desenvolveu reflexões acerca possibilidade ou não da institucionalização duradoura das emoções via relações de dominação. Preliminarmente, podemos afirmar que Weber tinha uma posição dúbia nesse sentido.

Sell (2018b) possui um argumento esclarecedor que nos ajuda a sustentar a tese de que há nos escritos weberianos sobre a dominação uma ordem afetiva. O intérprete afirma que a dominação carismática possui natureza bidimensional: ela pode tanto ser fonte de legitimidade de uma ordem quanto fonte de sua subversão. Em sua forma pura, o carisma firma-se sob a confiança pessoal de qualidades extracotidianas, especialmente no caráter heroico-exemplar. Aqui, são as características revolucionárias e subversivas que sobressaem. Quando em sua forma institucional, o carisma é despersonalizado - como o carisma gentilício [Gentilcharisma], o carisma hereditário [Erbscharisma] e o carisma de cargo [Amtscharisma]. Assim, ele despoja-se de sua efemeridade para, então, permanecer.

O carisma puro é a forma de dominação típica das crises políticas, religiosa ou econômica. Pessoas dotadas de qualidades consideradas excepcionais (seja de natureza ética, estética, política ou outra) possuem seu “carisma” reconhecido por seguidores. Os líderes carismáticos são capazes de mobilizar um grande número de pessoas que aceitem voluntariamente a dominação e acreditam na potencialidade de seu carisma para solucionar a crise (LEPSIUS, 2017). Exemplos 
de líderes carismáticos dotados de poderes considerados sobrenaturais são os magos (como o xamã), os profetas (como Maomé), os heróis guerreiros, artistas e demagogos (COLLIOT-THÉLÈNE, 2016).

A dominação carismática pura é forte e avassaladora, mas também tem uma legitimidade passageira. Por isso, ela não é capaz de manter uma ordem vindoura, mas é eficiente para derrubar ordens antigas e colocar-se em oposição aos aspectos estáveis da sociedade. Afinal, o líder carismático reivindica novos imperativos através de dispositivos não tradicionais. Isso porque sua dominação não se baseia em normas jurídicas ou acordos, mas no poder do "novo". Um dos poucos exemplos da história em que a dominação carismática conseguiu ser rotinizada é a Igreja Católica.

Assim, a ordem afetiva pode ser descrita, segundo Lepsius (2017) como uma estrutura afetiva e personalizada na qual há a coletivização das emoções. Isso porque o carisma (base da legitimidade dessa ordem) é excessivamente psicológico (MERQUIOR, 1990). Parsons (1947) evidencia com destreza que o carisma é a padronização de uma conduta de vida considerada uma virtude e personalizada em um líder. Seu poder depende do conhecimento contínuo de seus governados, esforço renovado de convencimento. Ela não é, portanto, a simples vontade pessoal do líder.

Em seu interior, a estrutura da organização carismática é caracterizada pela coexistência de relações rígidas (de comando e obediência) e de relações fluidas e flexíveis (de administração). Isso porque o líder requer, ao mesmo tempo, a autocapacitação de seguidores carismáticos e um grupo de gestão com membros pessoalmente selecionados por lealdade. Vale dizer que o quadro administrativo é ocupado por pessoas entusiasmadas com as características do líder (PARSONS, 1947). Isso faz com que a ordem carismática seja tanto centralista 
quanto descoordenada.

A transformação do carisma pessoal em carisma institucional requer mudanças profundas. É necessário, para tanto, que o quadro administrativo encabece o processo de rotinização ou pela via evolutiva (transformação da ordem carismática em ordem convencional ou jurídica) ou pela via da objetivação (supressão completa do carisma) (SELL 2018b). Quando adota-se o modelo evolutivo, é possível a manutenção do carisma ou por sucessão hereditária (tendência tradicional) ou pela escolha legal de um novo líder (tendência racional-legal) (PARSONS, 1947).

A ordem afetiva em sua forma carismática é comum em civilizações primitivas, especialmente naquelas em que o grau de burocracia é menor e as relações pautam-se em laços pessoais. Mas é possível verificar a existência da ordem carismática também em organizações contemporâneas (tais como em partidos políticos de democracias modernas).

É importante ressaltar que, frente a isso, os tipos possíveis de ordem não se esgotam nos três modelos de Grundbegriffe. O conteúdo de sentido aceito valida a ordem legítima, por isso é possível "falar de uma 'ordem econômica', em termos dos conteúdos de sentido das relações sociais referentes ao mercado, ou de uma 'ordem social', relativa aos conteúdos de sentido das relações sociais referentes a uma concepção de honra e a um estilo de vida dos agentes; ou ainda de uma 'ordem política', relativa aos conteúdos de sentido referentes à apropriação e luta pelo poder” (COHN, 2000, p. 31). 


\section{De 1913 a 1921: análise comparativa}

Em sua forma, tanto em 1913 quanto em 1921 Weber concebe a ordem como o ápice do nível macro de sua teoria. Cada relação social desenvolve um tipo específico de institucionalização regulamentada por uma ordem. Nisso ambos os textos convergem. Todavia, quando analisamos a substância do conceito de ordem social, verificamos mudanças. Em Kategorien Weber concebe a ordem como a regulamentação formal de uma relação social, quer dizer, como o elemento normativo a partir do qual as ações se orientam. Em Grundbegriffe Weber retoma a definição anterior complexificando-a e ampliando-a. Aqui, a ordem não é somente uma regulamentação de formas regulares de ação. Ela é, também, o conteúdo do sentido (tomado como uma máxima normativa) que orienta as ações no interior da relação. A ordem é vista como um conjunto de deveres e responsabilidades [Vorbindlichkeit] considerados "máximas obrigatórias para as ações” [Maximen] e modelos indicáveis [Vorbildlichkeit] para as relações decorridos de um conteúdo de sentido comum. Assim, a ordem permeia desde a relação subjetiva até a objetiva.

O elemento da validade, por exemplo, que era central na formulação de Kategorien haja vista as especificidades da ordem estabelecida, garantia a adequação das ações às normativas da ordem tendo em vista a possibilidade objetiva (a aceitação média das regularidades de ação). Mesmo que em Grundbegriffe o elemento da validade seja contemplado (especificamente no subtipo de ordem jurídica), sua importância foi diminuída. Em 1921 Weber incluiu formas mais abrangentes de ordem (como aquelas orientadas por máximas valorativas) ao atribuir à ordem social a característica moral-normativa (vigência e legitimidade) somada à característica cognitiva (representação). 
Isso indica que a ordem existe somente como uma imagem mental capaz de garantir a regularidade interna (sentido) e externa (do curso da ação). Tal regularidade está garantida pela vigência-legítima: a vigência, enquanto elemento factual, diz respeito a probabilidade de que as ações orientem-se pelo conteúdo de sentido da relação; a vigência advém da legitimidade, isso é, do sentimento de dever, padrão ético considerado moralmente bom.

Assim, ao apreciar a ordem estabelecida como o objeto de análise macrossociológica em 1913, em Kategorien Weber desenvolveu um conceito, digamos, “jurídico” de ordem. Em Grundbegriffe o autor admite a existência de ordens para além das institucionalizadas e formalmente estatuídas. Logo, o elemento jurídico deixa de ser tão central em 1921, e o elemento "político” do reconhecimento da legitimidade enquanto norma, máximas e deveres de qualquer espécie, passa a figurar como ponto nodal. Afinal, em 1921 é a ordem legítima que toma o centro da análise sociológica.

Outra mudança substantiva de sua teoria é de ordem tipológica. Em Kategorien temos a ordem estabelecida (ligada à ação em sociedade), e, se assumirmos a tese de Schluchter (2014), a ordem "pressuposta” (ligada a ação por acordo). Em Grundbegriffe, por outro lado, Weber funda um conceito único e geral de ordem e, a partir dele, subtipifica as ordens em legítima (convencional e jurídica), e, se assumirmos a tese de que o parágrafo 4 diz respeito às ordens sociais, em não legítima (econômico — regida por interesse). Por isso, fica visível que não há muitas continuidades efetivas entre um e outro texto no que tange a tipologia das ordens.

De todo modo, algumas aproximações são possíveis. Se assumirmos a tese de Schluchter (2014) de que há uma "ordem pressuposta” em Kategorien, é possível vislumbrar alguns elementos da ordem de 
1913 nas ordens econômica e convencional de Grundbegriffe. Especialmente no que diz respeito à pressuposição de que determinados comportamentos regulares serão efetivados na prática segundo as normas comuns da experiência. Sobre a ordem legítima de 1921, é possível encontrar um fundamento comum com a ordem estabelecida de 1913: o reconhecimento das normas fundamentais como máximas obrigatórias para as ações.

Por fim, vale perguntar: seria o conceito de ordem legítima, uma retomada do conceito de ordem estabelecida? Seria aquele primeiro a continuidade deste segundo? De fato, são fracas as evidências neste sentido, pois Weber não parece insistir no fato de que algo estabelecido seja sinônimo de algo moralmente obrigatório. Em termos explicativos, contudo, tudo leva a crer que a fonte mudança (ainda que não ruptura) efetuada aqui se deva ao fato de que Weber deixa de pensar a ordem somente em função do direito (ordem estabelecida) e passa a articular seu raciocínio a partir da política (ordem legítima). É por isso que temos a passagem da ordem estabelecida para a ordem legítima, sendo a ordem jurídica apenas um subtipo ao lado da ordem convencional e da ordem econômica.

\section{Referências}

ALBERT, Gert. Holismo Metodológico Moderado: uma interpretação weberiana do modelo macro-micro-macro. Política \& Sociedade, Florianópolis, v. 15, n. 34, 2016.

ALBERT, Gert et al. Das Weber-Paradigma. Tübingen: Mohr Siebeck, 2003.

COLLIOT-THÉLÈNE, Catherine. Prefácio. In: WEBER, Max. Le savant et le politique. La profession et la vocation de savant. La profession et la vocation de politique. Paris: La Découverte, 2003. 
. A sociologia de Max Weber. Petrópolis: Editora Vozes, 2016.

COHN, Gabriel. Max Weber. São Paulo: Editora Ática, 2000.

ESSER, Hartmut. Geltung, Legitimität und Herrschaft. In: Soziologie Spezielle Grundlagen: Institutionen. Frankfurt: Campus Verlag, 2000.

GRAFSTEIN, Robert. The Failure of Weber's Conception of Legitimacy: Its Causes and Implications. The Journal of Politics, v. 43, n. 2, 1981.

GROSSEIN, Jean-Pierre. De l'interprétation de quelques concepts wébériens. Revue française de sociologie, 2005a, n. 4, v. 46.

- Max Weber “à la française”? De la nécessité d'une critique des traductions. Revue française de sociologie, v. 46, n. 4, 2005b.

KALBERG, Stephen. Max Weber's Comparative-Historical Sociology Today: Major Themes, Modes of Analysis, and Applications.* London: Routledge, 2012.

LASSALE, Ferdinand. O que é uma Constituição. Belo Horizonte: Editora Líder, 2002.

LEPSIUS, Rainer. Max Weber and institutional theory. Suíça: Springer, 2017.

LUHMANN, Niklas. Legitimationdurch Verfahren. Darmstadt: Luchterhand Verlag, 1975.

MERQUIOR, José Guilherme. Rousseau e Weber: dois estudos sobre a teoria da legitimidade.* Rio de Janeiro: Editora Guanabara, 1990.

ORIHARA, Hiroshi. From “A Torso with a Wrong Head” to "Five Disjointed Body-Parts without a Head": A Critique of the Editorial Policy for Max Weber-Gesamtausgabe I/22. Max Weber Studies, v. 3, n. 2, 2003.

PARSONS, Talcott. The institutionalization of authority. In: WEBER, Max. The theory of social and economic organization. Nova York: Oxford University Press, 1947.

ROSSI, Pietro. Max Weber: una idea di Occidente. Roma: Donzelli, 2007.

SCHLUCHTER, Wolfgang. Handlung, Ordnung und Kultur. Heidelberg: Mohr Siebeck, 2005.

. Os conceitos sociológicos fundamentais: a fundamentação da sociologia compreensiva de Max Weber. In: O desencantamento do mundo: seis 
estudos sobre Max Weber. Rio de Janeiro: Editora UFRJ, 2014. . Max Weber Später Soziologie. Tübingen: Mohr Siebeck, 2016.

SELL, Carlos Eduardo. Weber no século XXI: desafios e dilemas de um paradigma weberiano. DADOS - Revista de Ciências Sociais, Rio de Janeiro, v. 57, n. 1, 2014.

. Resenha de: (MWG/12) - Sociologia Compreensiva e controvérsia sobre os valores. Escritos e Alocuções: 1908-1917. Tempo Social, revista de sociologia da USP, v. 30, n. 3, 2018a.

. Poder instituído e potência subversiva: Max Weber e a dupla face da dominação carismática. Revista Brasileira de Ciências Sociais, v. 33, n. 98, 2018b.

STAMMLER, Rudolf. Wirtschaft und Recht nach der materialistischen Geschichtsauffassung. Leipzig: Verlang von Veit \& Com., 1896.

VILLEGAS, Gil. Revisões e comentários. In: WEBER, Max. Economía y sociedad. México: FCE, 2014.

WEBER, Max. [MWG I/23] Wirtschaft und Gesellschaft: Soziologie (19191920). Knut Borchardt, Edith Hanke e Wolfgang Schluchter (Eds.) Tübingen: Mohr Siebeck, 2013.

. Economia e sociedade: fundamentos da sociologia compreensiva. Tradução de Regis Barbosa e Keren Elsabe Barbosa. Brasília: Editora Universidade de Brasília, 2015.

. Metodologia das Ciências Sociais. Tradução de Augustin Wernet. São Paulo: Cortez; Campinas: Editora Unicamp, 2016.

. [MWG I/12] Verstehende Soziologie und Werturteilsfreiheit: schriften und reden (1908-1917). Johannes Weiss e Sabine Frommer (Eds.) . Tübingen: Mohr Siebeck, 2018.

WEISS, Raquel; BENTHEIN, Rafael Faraco. 100 anos sem Durkheim, 100 anos com Durkheim. Sociologias, Porto Alegre, n. 44, 2017. 


\section{Resumo:}

Os estudos atualizativos dos escritos de Max Weber questionam seu estatuto de "individualista metodológico". Perseguindo esses esforços antirreducionistas, visualizamos em seus escritos metodológicos (nomeadamente, Kategorien de 1913 e Grundbegriffe de 1921) uma a macrossociologia das ordens sociais - que será objeto de discussão neste estudo. Em termos formais, em ambos os textos Weber concebe a ordem como o ápice do nível macro. Em termos substantivos, todavia, enquanto em 1913 a ordem é exposta como uma regulamentação da relação social que possui validade formal, em 1921, ao inserir o elemento moral-normativo da vigência legítima, a ordem é descrita como um conjunto de deveres considerados máximas obrigatórias para as ações. Quer dizer, Weber deixa de pensar a ordem somente em função do direito (ordem estabelecida) e passa a articular seu raciocínio a partir da política (ordem legítima).

Palavras-chave: Max Weber; macrossociologia; ordem social. 


\begin{abstract}
:
The updated studies of Max Weber's writings question his status as a "methodological individualist." By pursuing these anti-reductionist efforts, it is possible to see in his methodological writings (Kategorien, 1913 and Grundbegriffe, 1921) a macrosociology of social orders that will be discussed in the present paper. In formal terms, Weber conceives order as the macro-level culmination, in both texts. In substantive terms, the order is exposed as a regulation of the social relationship that has formal validity in 1913. However, in 1921, when there is an insertion of the moral-normative element of legitimate validity, the order is described as a set of duties considered as mandatory maximum for actions. Therefore, Weber stops thinking of order only in terms of the law (established order) and starts to articulate his reasoning from politics (legitimate order).
\end{abstract}

Keywords: Max Weber; macrosociology; social order.

Recebido para publicação em 07/04/2020.

Aceito em 05/10/2020. 